\title{
'Herói ou humano?': a construção do imaginário médico nas séries americanas
}

\section{'Hero or human?': the development of the medical profession image in American series}

\section{¿¿Héroe o humano?': la construcción del imaginario médico en las series norteamericanas}

\author{
Melina Meimaridis ${ }^{1, a}$ \\ melmaridis@hotmail.com | http://orcid.org/0000-0003-3481-817X \\ ${ }^{1}$ Universidade Federal Fluminense, Programa de Pós-Graduação em Comunicação. Niterói, RJ, Brasil. \\ a Mestrado em Comunicação pela Universidade Federal Fluminense.
}

\section{Resumo}

Este artigo busca analisar e discutir a construção dos profissionais de saúde nos seriados americanos, com o foco específico nos médicos. Defende-se que esses profissionais foram inicialmente construídos na televisão como heróis infalíveis devido à participação direta e indireta de instituições médicas. A revisão da literatura revela que esse modelo começou a dar sinais de desgaste nas décadas de 1970 e 1980, apresentando médicos passíveis de falhas, erros e até mesmo crimes. Argumentamos que as produções atuais, apesar de apresentarem profissionais 'mais humanos', continuam sendo influenciadas por organizações e instituições de saúde públicas e privadas, de modo a perpetuar um imaginário favorável do médico e da própria instituição. Para tanto, daremos atenção à recente participação da Hollywood Health and Society na ficção seriada televisiva.

Palavras-chave: televisão; ficção seriada; dramas médicos; instituição médica; representação; comunicação e saúde.

\begin{abstract}
This article aims to analyze and discuss the representation of health professionals in the American television series, with a specific focus on physicians. We defend that these professionals were initially presented as infallible heroes due to the direct and indirect participation of medical institutions. The literature review shows that this model began to deteriorate in the 1970 and 1980 os presenting fallible physicians, that were liable to errors and even crimes. We argue that the current production, despite presenting 'more human' professionals, continues to be influenced by public and private health organizations and institutions, in order to perpetuate a favorable image of doctors and the medical institution. In this regard, we will draw attention to the recent participation of the Hollywood Health and Society in television fictional series.
\end{abstract}

Keywords: television; serialized fictions; medical dramas; medical institution; representation; health communication. 


\section{Resumen}

El presente artículo se propone analizar y discutir la construcción de los profesionales de la salud en las series norteamericanas, con foco especial en los médicos. Se defiende que tales profesionales fueron inicialmente construidos en la televisión como héroes infalibles debido a la participación directa e indirecta de las instituciones médicas. La revisión de la literatura revela que ese modelo comenzó a dar señales de desgaste en las décadas de 1970 y 1980 presentando médicos pasibles de fallas, errores e incluso crímenes. Argumentamos que las producciones actuales, a pesar de presentar profesionales 'más humanos', continúan siendo influenciadas por organizaciones y instituciones de salud pública y privada para perpetuar un imaginario favorable al médico y a la propia institución. Para argumentar, daremos atención a la participación de Hollywood en la Health and Society en la ficción seriada televisiva.

Palavras clave: televisión; ficción en série; dramas médicos; institución médica; imaginario; comunicación y salud.

Contribuição dos autores: a autora é responsável por todo o texto.

Declaração de conflito de interesses: Este trabalho não apresenta conflito de interesses.

Fontes de financiamento: Coordenação de Aperfeiçoamento de Pessoal de Nível Superior (Capes).

Considerações éticas: Não há.

Agradecimento/Contribuições adicionais: Não há.

Histórico do artigo: Submetido: 19.jun.2017 | Aceito: 17.fev.2018 | Publicado: 30.mar.2018.

Apresentação anterior: Não houve.

Licença CC BY-NC atribuição não comercial. Com essa licença é permitido acessar, baixar (download), copiar, imprimir, compartilhar, reutilizar e distribuir os artigos, desde que para uso não comercial e com a citação da fonte, conferindo os devidos créditos de autoria e menção à Reciis. Nesses casos, nenhuma permissão é necessária por parte dos autores ou dos editores. 


\section{Introdução}

O consumo de narrativas ficcionais seriadas televisivas tem aumentado exponencialmente pelo mundo. Nesse contexto, as séries americanas têm se tornado um modelo reconhecido como um padrão transnacional a ser atingido por produções televisivas ao redor do mundo ${ }^{1-3}$. O atual momento da produção televisiva americana reúne séries dos mais variados tipos sendo produzidas por canais de televisão aberta, fechada e por serviços de streaming como a Netflix, tornando a disputa pela atenção e fidelização dos espectadores cada vez mais acirrada ${ }^{4-6}$. Nesse cenário, a temática médica tem sido recorrente nas séries americanas; em seu livro Playing Doctor ${ }^{7}$, Joseph Turow contabiliza ${ }^{i}$ o número de séries médicas afirmando que nos Estados Unidos existem mais de 100 delas desde 1951.

Para as autoras do livro Medicine's Moving Pictures ${ }^{8}$, as narrativas médicas abarcam todos os profissionais e todas as questões da saúde, não se prendendo a formatos e podem estar presentes em filmes, séries, contos, panfletos, vídeos educativos, entre outros. Os workplace dramas médicos são produzidos, recorrentemente, desde 1951 com a criação de City Hospital (CBS, 1951-1953) . Essas produções são rotineiramente abordadas por pesquisas de comunicação e saúde que buscam entender como se dá a representação da profissão médica ${ }^{9}$ e da instituição como um todo 7 . Analisam também como a recepção dessas representações afeta os relacionamentos médico-paciente dos espectadore ${ }^{10}$ e como essas séries podem transmitir informações de saúde pública a um grande número de pessoas ${ }^{11}$. O foco nessas produções pelo viés da comunicação e saúde se deve à noção de que, em vez de simplesmente entreter o público, os dramas médicos devem informar seus espectadores sobre a natureza do sistema médico, de seus profissionais e educá-los sobre questões de saúde, como patologias e seus métodos profiláticos, entre outras ${ }^{12}$. Assim, essas produções se tornam interessantes do ponto de vista da divulgação científica.

A razão por trás do caráter informacional dessas produções se deve, principalmente, pela crença de que produções de entretenimento podem educar seus espectadores e influenciar seus comportamentos ${ }^{13}$. De acordo com a pesquisa Porter Novelli HealthStyles realizada em 2005 nos Estados Unidos, que reuniu dados de espectadores constantes de dramas e comédias do horário nobre da televisão americana, $58 \%$ desses espectadores relataram "aprender algo novo sobre algum problema de saúde ou doença em um programa de TV”"14. Em outra pesquisa, produzida em 2000 pela mesma instituição, havia sido descoberto que $52 \%$ dos espectadores constantes confiavam e consideravam as informações de saúde nesses programas corretas, enquanto 26\% tinham dito que "programas televisivos de entretenimento exibidos no horário nobre estão entre as três principais fontes de informações sobre saúde" ${ }^{14}$.

Tendo em vista a importância dada pelos espectadores às séries médicas e a sua capacidade informativa, instituições públicas e privadas de saúde têm participado, ao longo dos anos, do desenvolvimento dessas narrativas. Alguns autores já relataram a participação reguladora da American Medical Association (AMA) na produção de séries a partir da década de $1950^{7,15}$. A AMA exigia a elaboração de narrativas que apresentassem os médicos positivamente, exaltando o profissionalismo e a ética da profissão médica ${ }^{16,17}$. No decorrer do tempo, representações menos favoráveis doss médicos e da própria instituição começaram a surgir. Séries como, por exemplo, St. Elsewhere (NBC, 1982-1988) apresentaram diversos aspectos negativos da profissão, caracterizando o ambiente médico como caótico, corrupto e injusto ${ }^{9}$. No entanto, atualmente, as instituições médicas ainda valorizam narrativas que apresentam um alto grau de precisão do conteúdo médico/científico ${ }^{17}$. Nos últimos anos, a Hollywood Health \& Society (HH\&S), organização pertencente ao departamento de comunicação e jornalismo da University of Southern California, tornou-se relevante ao prestar consultoria científica para mais de 90 séries televisivas entre 2009-2015 ${ }^{18}$.

\footnotetext{
i Em sua análise, Turow contabiliza qualquer programa televisivo que possuía um médico em papel recorrente, sendo ele ficção, reality, documentário, ou outros gêneros.
} 
Entender o processo de desenvolvimento do imaginário médico na televisão americana e o atual cenário, marcado pela participação da HH\&S é o foco deste artigo. Para isso, foi realizado um extenso levantamento bibliográfico, fruto de um esforço para contribuir para os estudos de ficção seriada no Brasil, principalmente para aqueles que se referem ao universo das séries médicas. As questões abordadas aqui se tornam relevantes no contexto brasileiro por dois principais motivos. Primeiramente, os dramas médicos americanos são extremamente populares no Brasil, como pode ser observado nas fanpages Grey's Anatomy BR e Grey's Anatomy Brasil no Facebook que contam com mais de trezentos mil e com duzentos mil seguidores, respectivamente. Em segundo lugar, nos últimos anos, a produção nacional tem tentado produzir suas próprias narrativas médicas, como a série Unidade Básica (Universal, 2016) que contou com uma curadoria de conteúdo e patrocínio do Hospital Sírio-Libanês ${ }^{19}$ em São Paulo, e a Sob Pressão (Globo, 2017), série homônima do longa-metragem de Andrucha Waddington. Apesar dessas produções, ainda é necessário entender como o formato se consolidou na televisão americana e quais são os códigos específicos desse formato narrativo.

Para melhor abordar o levantamento bibliográfico e atingir os objetivos propostos, o artigo foi organizado em três seções. Inicia-se apresentando uma breve contextualização histórica da imagem do médico na sociedade americana. Imagem esta que atualmente é glamorizada, mas que, no século XIX, era vista com maus olhos perante a maior parte da população. Ao mesmo tempo, apresenta-se o surgimento da narrativa ficcional médica. Em seguida, é apresentada a trajetória da consolidação do formato dos dramas médicos na televisão, dividindo em três principais momentos: os médicos heróis (1950-1960), o herói em transição (1970-1980), os médicos humanos (de 1990 até o presente). A metodologia utilizada foi uma análise de conteúdo embasada na literatura a ela pertinente, escolhendo enfocar apenas as principais produções médicas ficcionais de cada década, tanto do ponto de vista do sucesso da produção na televisão, quanto de sua contribuição analítica para a consolidação do formato. A terceira parte compete a uma discussão em torno dos dramas médicos atuais e a HH\&S, problematizando a participação e/ou intervenção da instituição nessas narrativas. Por último, são apresentadas as considerações finais.

\section{A construção da imagem do médico na sociedade americana}

A carreira médica é frequentemente glamorizada na sociedade ocidental; os mitos dos elevados salários e benefícios aliados ao status de 'estar salvando vidas' contribuem para uma visão fantasiosa da profissão. Entretanto, essa visão nem sempre existiu e, portanto, foi construída na sociedade através de diversos mecanismos. No caso americano, em particular, os médicos até o final do século XIX eram vistos como vigaristas, que muitas vezes faziam mais mal do que bem. O sociólogo Joseph Turow aponta que naquela época "muitos americanos se encolhiam só de pensar que teriam de pedir ajuda a um médico"7. Essa condição de desconfiança e desconforto era ocasionada, principalmente, pelo fato de que a grande maioria dos médicos da época pagava por seus diplomas e abria suas clínicas sem estarem propriamente qualificados para exercerem a profissão. Ademais, Turow ${ }^{7}$ aponta que a própria instituição médica, que ainda estava se organizando, não possuía credibilidade nem legitimidade perante a sociedade da época.

Em 1847, foi criada a já mencionada American Medical Association (AMA), uma organização que inicialmente não influenciou a visão que os americanos possuíam da profissão médica; porém, ao longo dos anos, com os avanços científicos e uma maior fiscalização, tornou-se uma das principais representantes da instituição médica nos Estados Unidos. No início do século XX, a AMA começou a investir em campanhas públicas para modificar a imagem do profissional de saúde, como, por exemplo, a campanha contra a automedicação 'Don't Dose Yourself', que enfatizava a importância de ir ao médico antes de consumir qualquer medicamento. Paralelamente, a organização pressionou as universidades de medicina por reformas 
curriculares. A maior participação dessa organização, aliada a investimentos no ramo privado da saúde e aos avanços científicos da época, contribuíram para mudar a imagem dos médicos na sociedade americana ${ }^{7,20}$.

Todas essas ações foram muito eficazes; entretanto, os meios de comunicação de massa como a literatura, o cinema, o rádio e, principalmente, a televisão tiveram um papel fundamental nesse processo. As narrativas médicas ficcionais se popularizaram nos Estados Unidos através dos contos de Frederick Schiller Faust, autor que já era famoso por seus contos western. Faust é reconhecido por ter criado a base da narrativa médica ficcional através do conto Interns Can't Take Money em 1936. O escritor, por já dominar os códigos do gênero western, buscou criar paralelos entre o papel do xerife e do médico, construindo, assim, o estereótipo de "médico-herói" na narrativa ${ }^{7,21}$.

O conto Interns Can't Take Money narra a história do Doutor Jimmy Kildare, um jovem humilde e recém-formado do interior dos Estados Unidos. O Dr. Kildare, que era virtuoso, extremamente ético e altruísta, buscava completar sua residência no hospital Mountview General Hospital em Nova Iorque. Em 1937, a Paramount Pictures comprou os direitos do conto e o transformou em um longa-metragem. O filme fez grande sucesso e Dr. Kildare começou a ser visto como o herói da sociedade moderna, que salvava seus pacientes a partir de seus conhecimentos científicos. Outros filmes, feitos pela Metro-Goldwyn-Mayer, sobre o Dr. Kildare, mostravam a importância da medicina na vida de cada cidadão, revestindo, assim, a instituição médica com camadas de importância e legitimação.

Apesar da popularidade dos filmes sobre o Dr. Kildare, na mesma época existiam outras produções com visões menos favoráveis da instituição médica, como, por exemplo, Dark Victory (1939). No filme, uma jovem sofre com fortes dores de cabeça e ao ser levada ao hospital é diagnosticada com um tumor no cérebro. A despeito de ser uma cirurgia complexa, seu médico Dr. Frederick Steele (George Brent) garante para sua paciente ter obtido sucesso no procedimento. Entretanto, ao longo do filme descobrimos que o médico não conseguiu remover o tumor em sua totalidade, optando por mentir para sua paciente, que morre no final do longa-metragem. A produção foi extremamente criticada pela AMA, que começou a pressionar os estúdios por representações mais 'precisas' de doenças, tratamentos e inclusive a um comportamento mais profissional por parte dos médicos7 . Como resultado das imposições da AMA as narrativas ficcionais médicas começaram a desempenhar uma função mais informativa perante a sociedade ${ }^{8}$. Embora algumas narrativas com visões desfavoráveis da instituição ainda circulassem, a AMA conseguiu fazer grande pressão contra determinadas obras, inviabilizando qualquer produção que se mostrasse contrária à instituição e/ou à classe médica.

Com o sucesso dos filmes sobre o Dr. Kildare e com o surgimento do rádio e da televisão, houve uma adaptação dessa narrativa ao formato seriado da rádio novela e das séries televisivas. No rádio, a série The Story of Dr. Kildare (MGM, 1949) contava as histórias do jovem Jimmy Kildare e suas aventuras de vida ou morte no hospital. Com a produção, determinadas características dos dramas médicos foram se solidificando, o ambiente central da narrativa era o hospital, os principais personagens eram médicos (homens brancos), enfermeiras, pacientes e seus familiares ${ }^{21}$. Na grande maioria dos casos os pacientes eram mulheres e crianças, tendo em vista o maior apelo melodramático desses personagens.

\section{Os dramas médicos da televisão americana}

De acordo com Meimaridis ${ }^{22}$, entre 1950 e 2016, foram produzidas na televisão americana 100 séries médicas. A pesquisadora, diferente de Turow ${ }^{7}$, considerou apenas as séries ficcionais médicas americanas ambientadas em hospitais, clínicas particulares e afins, desse modo não contabilizando os dramas policiais que possuem médicos investigadores, nem as soap operas médicas, os programas médicos não ficcionais como documentários - e os reality shows. Devido à numerosa quantidade de dramas médicos televisivos optamos por agrupá-los em três momentos distintos. Observamos que a imagem do médico passou de 
um herói, quase um deus, a uma visão mais 'humana' do profissional ao longo das seis décadas dessas produções na TV americana. Abaixo abordaremos brevemente $21^{i i}$ produções distintas que pertencem a três momentos para ilustrar a transição do 'médico-herói’ para um profissional mais ‘humano'.

\section{Os médicos heróis (1951-1960)}

Em 1951, a CBS estreou City Hospital, a primeira série médica televisiva; porém, devido à baixa audiência, a produção foi rapidamente cancelada. Três anos depois, a série Medic (NBC, 1954-1956) estreou com um estilo documental e sendo filmada em um hospital de verdade, chegando, inclusive, a exibir trechos de cirurgias reais. Ao longo de suas duas temporadas, a série expôs um mundo que o público ainda não tinha visto, explorando o funcionamento do hospital por dentro e revelando como alguns procedimentos cirúrgicos eram realizados. Ademais, a produção ainda foi exibida inicialmente sem intervalos comerciais para enfatizar a tensão dramática e reforçar seu estilo documental.

O drama Medic ainda inovou por incluir médicos na equipe de roteiristas, que tinham o direito da aprovação final do roteiro, demonstrando, desse modo, a clara influência da AMA na trama da série. Ao longo de 59 episódios quase nenhum paciente morreu e, caso algum enfermo tivesse uma doença terminal, sua morte não era exibida, ficando apenas subentendida ${ }^{20}$. A baixa taxa de mortalidade das séries médicas era uma exigência da AMA ${ }^{\text {iii }}$, juntamente com o pedido de que os médicos falassem apenas se utilizando da norma culta e que fossem sempre apresentados da forma mais profissional possível. Apesar da proximidade com a AMA e da direta participação de médicos na elaboração da narrativa, a série teve apenas duas temporadas, porque foi considerada muito provocativa por outras instituições sociais, como, por exemplo, a Igreja Católica, que se opôs diretamente à exibição de uma cesariana em um dos episódios da série7.

Nos anos seguintes, outras séries médicas foram produzidas seguindo os modelos consagrados da narrativa médica, como, por exemplo, Ben Casey (ABC, 1961-1966) e Dr. Kildare (NBC, 1961-1966). Ambas as produções reforçaram a imagem do 'médico-herói' apresentando médicos (homens brancos) extremamente éticos, altruístas e dedicados aos seus pacientes. Para Jacobs ${ }^{20}$, ambas as produções continuavam a tranquilizar seus espectadores sobre o profissionalismo dos médicos e os avanços científicos da medicina. Além disso, as séries ainda encorajaram os membros da AMA a revisarem os roteiros de cada episódio para garantirem "autenticidade médica e profissional" ${ }^{21}$, chegando a receberem o "selo de qualidade" de autoridades médicas" ${ }^{23}$ e o "selo permanente de aprovação da AMA"7.

Durante duas décadas, as séries médicas variaram pouco em suas representações, consolidando-se, assim, o estereótipo do 'médico-herói' na figura de um homem branco, muito profissional, inteligente e prestativo. Ao mesmo tempo, as personagens femininas recorrentemente eram relegadas aos papéis de "esposas, namoradas, pacientes e enfermeiras" ${ }^{24}$. Nesse sentido, Turow ${ }^{7}$ afirma que frequentemente uma "donzela caía doente nos braços do solícito e atraente Dr. Kildare". Paralelamente, Philips ${ }^{24}$ argumenta que o estereótipo do 'medico-herói' era apoiado por um elenco de enfermeiras que permitiam ao médico exercer toda a sua "expertise médica" ${ }^{24}$. Posteriormente, Feasey ${ }^{21}$ indica que os poucos dramas na época que incluíram médicas como atrizes convidadas dedicavam parte da narrativa do episódio ao conflito da personagem entre exercer a profissão, cuidar de sua casa e ter relacionamentos amorosos.

Apesar da frequente representação feminina nos dramas médicos em papéis coadjuvantes, houve algumas tentativas de focar produções em torno de enfermeiras e médicas, como, por exemplo, The Nurses (CBS, 1962-1965) e Julie Farr, M.D. (ABC, 1978). Apesar do esforço, a série The Nurses teve uma fraca recepção do público em sua primeira temporada, sendo modificada para The Doctors and Nurses a partir ii A escolha dessas produções foi realizada tendo dois princípios em mente: 1) sucesso de audiência e/ou crítica. 2) Capacidade
transgressora da produção para modificar o formato ou contribuir para sua consolidação.

iii A baixa taxa de mortalidade nas séries médicas era uma imposição da AMA, visto que a organização se preocupava com o possível "pânico generalizado" caso os espectadores vissem pacientes morrendo nas mãos de médicos inaptos?. 
de seu segundo ano. A mudança resultou em um aumento da audiência e a produção ficou no ar por um total de quatro anos. Já a narrativa da Dra. Julie Farr não chegou à segunda temporada, tendo apenas alguns episódios exibidos devido à sua baixa audiência. $\mathrm{O}$ fracasso das séries protagonizadas por mulheres confirmou para os executivos das emissoras que dramas médicos de sucesso tinham que ser protagonizados por homens, uma vez que o público masculino era "desestimulado com mulheres protagonistas"7. Ademais, o insucesso de uma série protagonizada por enfermeiras também desmotivou produções focadas em outros profissionais da saúde ${ }^{\mathrm{iv}}$.

No fim da década de 1960, outros dramas médicos foram produzidos, como Medical Center (CBS, 1969-1976) e Marcus Welby, M.D. (ABC, 1969-1976). Ambas as produções perpetuaram o estereótipo do 'médico-herói' e continuaram seguindo as 'cartilhas' da AMA.

\section{O herói em transição (1970-1980)}

No início da década de 1970 estreou a série $M^{*} A^{*} S^{*} H$ (CBS, 1972-1983), adaptação do premiado filme homônimo de 1970. A produção foi considerada um divisor de águas no formato7, acompanhando o dia a dia de um grupo de médicos e enfermeiras da base militar 4077 durante a Guerra da Coreia na década de 1950. A trama não era centrada no ambiente hospitalar, apesar da existência de espaços clínicos, como a tenda em que eles realizavam as cirurgias em seus pacientes. Diferentemente dos dramas do passado, em $\mathrm{M}^{*} \mathrm{~A}^{*} \mathrm{~S}^{*} \mathrm{H}$ os médicos atendiam, principalmente, soldados feridos, e não mais mulheres e crianças. $\mathrm{O}$ foco narrativo da série era nas vidas dos médicos, enfatizando seus relacionamentos pessoais e profissionais. Além disso, a produção ainda deixou em segundo plano as patologias, visto que na maioria dos episódios os médicos tratavam apenas de soldados feridos.

Apesar de ser considerada uma sitcom por muitos, a série $M^{*} A^{*} S^{*} H$ se caracteriza como uma das primeiras dramédias de sucesso da televisão americana, incluindo momentos de descontração e humor entre as sequências dramáticas. Em um típico episódio da série, um soldado ferido chegava à base militar e os médicos e enfermeiras corriam para salvar sua vida e, em seguida, os espectadores viam como esses profissionais celebravam o sucesso dos procedimentos cirúrgicos ou lidavam com a morte do paciente. Para Turow', a audiência pôde se identificar com um médico que, após um dia 'difícil no trabalho', relaxava tomando uma cerveja. A possibilidade dessa identificação aproximava o profissional do homem comum, quebrando a visão idealizada e inatingível do médico na ficção seriada televisiva americana.

Seguindo o caminho inaugurado por $M^{*} A^{*} S^{*} H$, surgiu na década de 1980 outro drama médico focado nas vidas conturbadas de seus profissionais, a série St. Elsewhere (NBC, 1982-1988). A produção, que foi considerada uma "versão médica" 25 do drama policial de sucesso Hill Street Blues (NBC, 1981-1987), representava versões falhas e mais humanas de médicos. Para Josh Brand, criador de St. Elsewhere, os médicos eram representados até então de forma 'icônica', mas agora em sua série eles "são humanos"7. Já para o presidente da NBC na época, Brandon Tartikoff, a série apresentava uma visão "desconfortavelmente pessimista dos hospitais"”.

Tanto St. Elsewhere quanto Hill Street Blues criticavam suas instituições, ao apresentarem as dificuldades enfrentadas pelos seus profissionais, que agora se deparavam com um sistema corrupto ${ }^{15}$. Alguns autores já argumentaram que o surgimento de séries com visões críticas às instituições se tornou recorrente entre as décadas de 1970 e 1980, principalmente devido a uma desconfiança generalizada em instituições9,26

iv Apesar de poucos dramas mé dicos focados em outros profissionais da saúde, nota-se que ao longo dos anos algumas produções protagonizadas por enfermeiras foram realizadas como, por exemplo, Nurse (CBS, 1981-1982), Nurses (NBC, 19911994) e, mais recentemente, HawthoRNe (TNT, 2009-2011) e Nurse Jackie (Showtime, 2009-2015). Esta última recebeu diversos prêmios da crítica americana, chegando a ficar seis anos no ar. 
no pós-Guerra do Vietnã (1955-1975) e em razão do escândalo do Watergatev. No caso específico das séries médicas, Jacobs ${ }^{20}$ aponta que durante esse período houve uma queda de “confiança nas instituições médicas, ciência médica e em médicos”. As séries médicas da década de 1980, portanto, acompanhando esse estado de desconfiança, introduzem nas narrativas a figura do administrador do hospital, que se importava mais com a rentabilidade do estabelecimento do que com a vida de seus pacientes.

O drama médico St. Elswhere conta a história de um hospital público decadente em um dos bairros mais pobres de Boston. Ao longo de suas seis temporadas, a série abordou diversos temas considerados tabu na sociedade americana, desde a crise da Aids, o homossexualismo, o estupro, a eutanásia, entre tantos outros. Além disso, o drama ainda focava dilemas pessoais e profissionais dos médicos e das médicas do hospital St. Eligius como, por exemplo, divórcio, assédio, suicídio, baixos salários, e a longa jornada de trabalho²7. A série apresentou diferentes estereótipos de médicos, entre eles o de "um sobrevivente de câncer, um negro bem-sucedido e um ex-dependente químico em recuperação"9.

A produção comumente colocava em xeque os médicos, seus pacientes e a administração hospitalar, enfatizando as dificuldades vividas pelos profissionais de saúde no dia a dia do hospital. Em seis temporadas, os médicos, que até então eram apresentados como heróis intocáveis, se tornaram vítimas e agressores. No primeiro caso, diversos profissionais de saúde sofreram com estupro (Dra. Cathy Martin, Dr. Jack Morrison, enfermeira Shirley Davis), depressão e/ou suicídio (Dra. Wendy Armstrong), agressão física (Dr. Jack Morrison, Dr. Wayne Fiscus) e câncer (Dr. Daniel Auschlander, enfermeira Helen Rosenthal). Ao mesmo tempo, outros personagens estupravam médicas e enfermeiras do hospital (Dr. Peter White), cometiam assassinato (enfermeira Shirley Davis), perpetravam erros clínicos que levavam seus pacientes à morte (Dra. Wendy Armstrong, Dr. Phillip Chandler), consumiam drogas (Dr. Peter White) e tinham distúrbios alimentares (Dra. Wendy Armstrong), entre outros exemplos. Todas essas características contribuíram para que o ideal do 'médico-herói', centralizado na figura de um único profissional, fosse substituído por uma equipe médica que, apesar de suas falhas individuais, se esforçava em conjunto para salvar vidas ${ }^{21}$.

Apesar de apresentar médicos mais humanos e falhos, St. Elsewhere reforçou o discurso da 'vocação médica', como pode ser visto no episódio 'Craig in Love' (to1;ep20 vi). Nele, o Dr. Phillip Chandler (Denzel Washington), ao se referir ao exercício da profissão médica, desabafa com um de seus colegas perguntando "Por que nós fazemos isso?”; o Dr. Victor Ehrlich (Ed Begley Jr.) apenas responde “Porque somos loucos”. Ao longo do episódio acompanhamos os dilemas do Dr. Chandler que está sendo processado por malversação médica, ao mesmo tempo em que tem de cuidar e tratar de outros pacientes. No fim do episódio fica clara a ideia de que a profissão médica pode não ser tão glamorosa quanto o Dr. Kildare quis fazer parecer, porém os médicos são indivíduos com o dom de curar, mesmo que isso signifique uma vida de sacrifícios.

\section{O médico humano (de 1990 até o presente)}

A década de 1990 viu surgir dramas médicos protagonizados por grandes elencos como, por exemplo, Heartbeat (ABC, 1988-1989) e Chicago Hope (CBS, 1994-2000). Em linhas gerais, essas produções focavam suas narrativas em equipes de médicos (homens e mulheres) e outros profissionais de saúde. Ao mesmo tempo, séries centradas na figura de um único médico dedicado e excepcional continuaram sendo produzidas, como: Dr. Quinn, M.D. (CBS, 1993-1998), série protagonizada por uma médica atuante em 1867, e Doogie Howser, M.D. (ABC, 1989-1993), produção que acompanha a vida do adolescente prodígio Douglas Howser que, com 14 anos, se formou na faculdade de medicina.

\footnotetext{
v Escândalo político do início da década de 1970 que revelou o envolvimento do presidente Richard Nixon no assalto ao Comitê Nacional Democrata. Um pedido de impeachment foi iniciado no Congresso, porém Nixon optou por renunciar.

vi "t" é referente à temporada e "ep" ao episódio, assim t01; ep20 seria o vigésimo episódio da primeira temporada. Esse modelo será utilizado ao longo deste artigo.
} 
Um dos principais dramas médicos da década de 1990 foi $E R$ (NBC, 1994-2009), série centrada em torno do cotidiano da sala de emergência de um hospital de Chicago. Esse espaço em que médicos tomam decisões de vida ou morte rotineiramente se mostrou um ambiente muitas vezes caótico ${ }^{22}$. Esse ambiente desordenado proporcionou um ritmo acelerado à trama, que ganhou agilidade e diversas tensões narrativas enquanto os médicos buscavam atender seus pacientes. Nota-se que a série era marcada por uma maior presença e participação dos pacientes, visto que no decorrer de um único episódio os médicos atendiam diversos enfermos. A interação entre os médicos e seus pacientes era, na maioria das vezes, negativa. Para Tapper ${ }^{9}$, os pacientes eram apresentados constantemente reclamando dos longos períodos de espera para o atendimento, ao mesmo tempo em que se indignavam quando eram atendidos de forma breve e corriqueira.

Paralelamente, a busca do equilíbrio entre a vida pessoal e a vida profissional desses profissionais tornase um tema dominante em $E R$. Esse equilíbrio é apresentado como um ideal praticamente inatingível, uma vez que as demandas da profissão médica obrigam o profissional a seguir uma rotina caótica e extremamente cansativa, marcada por longos plantões e pela pressão por salvar vidas. Nesse contexto, esses profissionais são questionados por privilegiarem seu trabalho - salvar vidas - em detrimento de suas vidas pessoais. O dilema pode ser evidenciado na interação entre a médica Dra. Susan Lewis (Sherry Stringfield) e uma paciente no episódio piloto (to1;epo1) de $E R$. Ao ser questionada pela paciente se ela era casada, a médica apenas responde: "Não, eu sou uma médica". A Dra. Lewis parte do pressuposto de que as demandas da profissão médica são tantas, que impedem os médicos de atingirem a realização matrimonial.

Apesar das séries médicas inicialmente não apresentarem fatalidades em suas narrativas ${ }^{7,15}$, séries como St. Elsewhere e Chicago Hope começaram a incluir uma maior quantidade de mortes em suas produções, tanto de pacientes, quanto dos próprios médicos. $O$ drama $E R$ foi a primeira série a mostrar uma grávida morrendo na ficção televisiva americana7. O caso ocorreu no episódio intitulado 'Love's Labor Lost' (to1;ep17), no qual uma grávida vai à sala de emergência com alguns incômodos, e é atendida pelo Dr. Green (Anthony Edwards) que erra o diagnóstico, enviando a moça de volta para casa. A grávida volta algum tempo depois com sérias complicações e o staff da sala de emergência passa o episódio inteiro tentando salvar a vida da paciente e a de seu bebê. No desenrolar da trama novas complicações surgem, apesar de todo o esforço dos profissionais de saúde. Ao término do episódio, a mulher e o seu bebê morrem. O médico errou no seu diagnóstico inicial e após tentar, incansavelmente, realizar todas as medidas possíveis para salvar a paciente, ela não resistiu. A questão apresentada por $E R$ nesse episódio era maior do que explorar a falibilidade dos médicos e de outros profissionais de saúde; era, sim, revelar que pacientes irão morrer e nenhum médico pode evitar essa realidade. A morte, desse modo, é apresentada como uma condição humana que afeta todos os indivíduos, pacientes e médicos.

O início dos anos 2000 foi marcado pelo surgimento de três novas produções médicas de sucesso: a dramédia Scrubs (NBC, 2001-2008/ABC, 2009-2010), e os dramas House, M.D. (FOX, 2004-2012) e Grey's Anatomy (ABC, de 2005 até o presente). Apesar do tom cômico, Scrubs se destacou por apresentar uma visão mais realista da experiência dos residentes clínicos e cirúrgicos, ao acompanhar o treinamento do residente Jonathan Dorian (Zach Braff) e de seu amigo cirurgião Christopher Turk (Donald Faison). Paralelamente, a produção é exaltada por apresentar, de forma simples, questões éticas e jurídicas relativas à prática médica ${ }^{28}$.

Apesar da preferência por representações favoráveis de médicos ao longo das décadas, em 2004 a FOX lançou o drama procedural ${ }^{\text {vii }}$ House, M.D., com um protagonista médico extremamente 'rude' e 'maleducado'. O desgosto dos pacientes e de seus familiares pelo médico é recíproco, uma vez que o Dr. House (Hugh Laurie) se configura como uma pessoa misantrópica (to1:epo7), chegando a afirmar por diversas

vii Procedural é um modelo narrativo em que os episódios da série apresentam narrativas independentes umas das outras. Cada episódio contém uma situação específica na qual os personagens principais devem solucionar até o fim do mesmo. Modelo geralmente associado ao gênero dos workplace dramas. 
vezes que não gosta de interagir com seus pacientes. Porém, embora demonstre essas características negativas no campo ético da profissão, o Dr. House ainda era um médico extremamente capaz, sendo inclusive considerado o médico mais ‘confiável' na televisão pelos espectadores'. Assim, embora passível de críticas, a série House, M.D. ainda pode se configurar, em certa medida, como uma representação favorável da medicina e de sua instituição ${ }^{21}$, com médicos qualificados lidando com o processo de diagnóstico de doenças raras e casos clínicos complexos. O foco da narrativa será, portanto, nas patologias dos pacientes e no trabalho do Dr. House e de sua equipe para diagnosticar e tratar corretamente essas doenças.

Já Grey's Anatomy acompanha a trajetória da doutora Meredith Grey (Ellen Pompeo) e de outros internos $^{\text {viii }}$ no programa cirúrgico do Seattle Grace Hospital. O drama busca apresentar as dificuldades que os médicos possuem de conciliar suas carreiras profissionais com suas vidas pessoais, mais especificamente, suas vidas amorosas. A busca do equilíbrio entre a vida pessoal da médica e a profissional se torna o foco da narrativa. Ao mesmo tempo, o ambiente cirúrgico é apresentado como um dos mais competitivos e desafiadores entre as especialidades médicas. Os episódios contam com um voice-over da protagonista refletindo sobre questões da sua percepção acerca da existência humana; esses apontamentos são, em linhas gerais, guias temáticos para os dramas e dilemas enfrentados pelos personagens naquele episódio.

Com o fim de ER, Scurbs e House, M.D., os canais da televisão americana estão à procura de uma nova série médica de sucesso para preencher o 'vazio'. Nos últimos anos foram produzidas diversas séries com essa motivação como, por exemplo, Emily Owens M.D. (CW, 2012-2013), Monday Mornings (TNT, 2013), Black Box (ABC, 2014), The Knick (Cinemax, 2014-2015), Rosewood (FOX, 2015-2017), Heartbeat (NBC, 2016), Mercy Street (PBS, 2016-2017) e Pure Genius (CBS, 2016-2017). Todas foram canceladas depois de apenas uma ou duas temporadas. Apesar desses insucessos, atualmente outras séries médicas estão atraindo espectadores como, Chicago Med (2015 até o presente), Code Black (CBS, 2015 até o presente) e The Good Doctor (ABC, 2017 até o presente).

\section{A Hollywood Health \& Society e os dramas médicos contemporâneos}

Tendo em vista a construção do imaginário médico na televisão americana e o papel regulador da AMA ao longo dos anos é incontroverso propor a existência de uma significativa relação entre a instituição médica e a indústria televisiva. Apesar de uma diminuição da intervenção da AMA nas últimas décadas, outros agentes têm encontrado espaço de influência nas séries médicas americanas, como a Hollywood Health \& Society estabelecida em 2001 por meio do financiamento do Centers for Disease Control and Prevention (CDC). Em 1994, o CDC reuniu um painel de peritos para discutirem a cooperação do órgão com a indústria do entretenimento e, em 1997, começou um projeto que fornecia informações e consultores para escritores de Hollywood. Atualmente, o projeto faz parte do Norman Lear Center, centro de pesquisa pertencente ao departamento de Comunicação e Jornalismo da University of Southern California. A HH\&S declara que "fornece aos profissionais da indústria do entretenimento informações precisas e oportunas para enredos sobre saúde, segurança e segurança nacional”²0. A organização presta seus serviços gratuitamente para os roteiristas e produtores de ficção seriada televisiva, sendo financiada por diversos órgãos e agências federais, além de outras organizações sem fins lucrativos.

A proposta por trás da HH\&S é motivada pelos estudos sobre Entertainment-Education ${ }^{\text {ix }}$ (E-E), termo que é definido como "o posicionamento intencional de conteúdo educacional em mensagens de entretenimento" 29 e que tem como propósito “divulgar ideias para promover mudanças comportamentais

\footnotetext{
viii Nos Estados Unidos, o processo de residência é dividido em sete anos; no primeiro, os novatos são chamados de internos e, a partir do segundo, são chamados de residentes.

ix Para mais informações sobre Entertainment-Education ver: Brodie, Foehr, Rideout, Baer, Miller, Flournoy et al. ${ }^{30}$, Bouman ${ }^{31}$. Valente, Murphy, Huang, Gusek, Greene e Beck ${ }^{32}$.
} 
e sociais”29. Na esfera da saúde pública, Hether e Murphy'13 apontam que a estratégia do E-E "foi adotada como uma forma econômica de comunicar informações sobre saúde em um formato envolvente para um público de massa”. Com essa visão, a HH\&S realiza anualmente consultorias, eventos, briefings, e até visitas guiadas, de forma a contribuir para a elaboração de tramas mais precisas sobre questões de saúde e segurança pública. Ao mesmo tempo, a HH\&S realiza todos os anos o Sentinel Health Awards ${ }^{18}$, com o apoio do CDC, premiando as produções televisivas e cinematográficas que educam e estimulam os espectadores a optarem por uma vida mais saudável.

A HH\&S tem crescido graças aos seus patrocinadores e a organização trabalhou com mais de 90 programas entre 2009-2015, abordando em torno de 700 tópicos distintos sobre saúde e medicina ${ }^{18}$. A instituição presta consultoria para diversas séries, não só as médicas; por exemplo, trabalhou com os escritores de Breaking Bad (AMC, 2007-2013) para representarem de forma precisa a evolução do câncer do protagonista ${ }^{\mathrm{x}}$ O financiamento da organização, que varia de 300 a 500 mil dólares por ano, é visto como um investimento em saúde pública por algumas instituições federais.

É possível observar que por trás da parceria entre a HH\&S e a indústria audiovisual americana existe uma relação mutualística. Ao passo que a HH\&S colabora com os produtores e roteiristas de séries televisivas fornecendo conteúdo legitimado e preciso, as produções abordam determinadas questões consideradas pertinentes pela instituição. Paralelamente, a organização, por estar filiada a uma instituição acadêmica, realiza testes e monitora o desenvolvimento e a recepção das tramas para as quais eles prestaram consultoria, como o trabalho de Hether, Huang, Beck, Murphy e Valente ${ }^{33}$, em que os pesquisadores analisaram o impacto de duas storylines sobre câncer de mama (especificamente a mutação do gene BRCA1) em Grey's Anatomy e ER. De acordo com os autores, a elaboração das tramas veio após a HH\&S realizar um painel sobre o assunto para os roteiristas desses programas, os quais tiveram a liberdade e independência de escolherem como o conteúdo seria apresentado nas suas respectivas séries ${ }^{33}$. A história sobre as pacientes com o gene do BRCA1 foi contada em ambas as produções e os pesquisadores através de um survey puderam analisar a recepção do público a essas storylines. Os resultados indicaram que a falta de controle do pesquisador sobre a trama pode ocasionar a exibição de mensagens negativas como, por exemplo, em $E R$ a Dra. Lockhart (Maura Tierney) admite nunca ter feito uma mamografia apesar de ter um histórico de câncer de mama em sua família. Entretanto, a recepção de ambas as tramas forneceu evidências de que o Entertainment-Education pode ser "um veículo eficaz para transmitir fatos importantes sobre questões de saúde complexas" 33 tendo em vista que muitos dos entrevistados alegaram ter aprendido sobre a condição após terem sido expostos aos episódios das séries.

A questão da independência dos roteiristas e da consequente falta de controle por parte da HH\&S foi apontada também no estudo realizado por Movius, Cody, Huang, Berkowitz e Morgan ${ }^{11}$ em que consultores da organização trabalharam com roteiristas de House, M.D., Grey's Anatomy e das séries policiais CSI:NY (CBS, 2004-2013) e Numb3rs (CBS, 2005-20010) desenvolvendo tramas que envolviam transplantes. No artigo, Movius, Cody, Huang, Berkowitz e Morgan ${ }^{11}$ apontam que, no caso de Numb3rs, os roteiristas da série queriam abordar a questão do transplante associada à venda de órgãos no mercado negro. Os consultores da HH\&S explicaram que não existia um mercado negro nos Estados Unidos, sugerindo que "o episódio em vez disso enfatizasse a elevada demanda por doações de órgãos, uma vez que as populações vulneráveis nos EUA podem ser suscetíveis a mitos e retratos imprecisos associados a transplantes de órgãos na televisão" ${ }^{11}$. Em 2006, o episódio 'Harvest' (to2;ep14) foi exibido contando com uma história sobre o mercado negro de órgãos nos Estados Unidos e a questão do tráfico humano. Movius, Cody, Huang, Berkowitz e Morgan ${ }^{11}$ apontam que "apesar da premissa imprecisa, este episódio também forneceu consideráveis informações precisas sobre o número de pessoas na lista de espera de transplantes".

x https://www.theatlantic.com/health/archive/2014/09/hollywoods-health-experts/380539/ 
Com isso em mente, a HH\&S se posiciona de modo diferente da AMA, visto que a primeira é estruturada como uma organização acadêmica em prol da divulgação de conteúdos científicos precisos relativos à saúde pública. Já a segunda é uma instituição privada, que defende, primordialmente, os interesses da classe médica através de sua participação reguladora na ficção seriada televisiva. Embora exista diferença entre ambas as organizações, observa-se que a HH\&S é financiada por outras instituições médicas e agências federais como, por exemplo, o CDC, o National Cancer Institute (NCI), o Health Resources Services Administration Division of Transplantation, as quais, certamente, prezam uma representação favorável de suas organizações. A contínua representação favorável dos profissionais de saúde e da instituição médica como um todo até os dias de hoje foi identificada no estudo de $\mathrm{Foss}^{17}$. A sua pesquisa concluiu, após codificar 536 episódios de quatro dramas médicos contemporâneos (Chicago Hope, ER, Grey’s Anatomy e House, M.D.), que apesar das mudanças na representação dos médicos, são poucas as narrativas que responsabilizam o médico por erros, e o número que culpabiliza a instituição médica é ainda mais modesto. Nesse sentido, a autora afirma "eles raramente cometiam erros clínicos, o que indica que esses personagens poderiam superar a adversidade sem sacrificar a qualidade do atendimento ao paciente" ${ }^{{ }_{17}}$.

\section{Considerações finais}

Os dramas médicos têm sido um dos modelos narrativos mais populares na história da televisão americana $^{22}$, conquistando e encantando fãs ao redor do mundo, e especificamente no Brasil. Entretanto, observa-se uma certa ausência de narrativas ficcionais médicas na televisão nacional, com exemplos pontuais como Obrigado Doutor (Globo, 1981), Mulher (Globo, 1998-1999) e Beleza S/A (GNT, 2013). Em 2016, a Universal Channel exibiu a produção nacional Unidade Básica centrada nos atendimentos do SUS. De acordo com a crítica, a série se esforça para fornecer ao público histórias favoráveis "com um olhar positivo, e, de certa forma, romantizado, das atividades de uma Unidade Básica de Saúde. Focando exclusivamente na relação médico e paciente, ela tenta estimular a confiança do público nos trabalhos que são realizados por eles" ${ }^{34}$. A série aborda acontecimentos reais e seus atores visitaram Unidades Básicas de Saúde para compreenderem o dia a dia desses estabelecimentos. Entretanto, ainda são necessários estudos acadêmicos específicos que abordem a série e a recente produção global Sob Pressão na tentativa de compreender como a instituição médica brasileira tem sido representada nessas produções. Olhar as parcerias que essas séries têm firmado, como no caso de Unidade Básica que foi patrocinada pelo Hospital Sírio-Libanês em São Paulo, pode ser um bom lugar para começar.

No que compete aos dramas médicos, ainda é preciso dominar tanto os códigos textuais do modelo narrativo quanto compreender sua posição dentro do circuito indústria-público-instituições para que o Brasil consiga produzir narrativas que sejam reconhecidas como pertencentes ao formato. Esse domínio é importante também para que essas produções usufruam das possíveis relações do circuito, as quais têm se provado um dos grandes trunfos dos dramas médicos no exterior ${ }^{7,17,28}$. Nesse sentido, apresentou-se como as séries médicas americanas criaram um imaginário favorável dos médicos e da instituição médica, principalmente através da influência reguladora direta da AMA, e de forma mais indireta através da HH\&S, que fornece conteúdo legitimado para a elaboração das tramas. Em linhas gerais, as produções americanas mencionadas neste artigo continuam a reforçar as visões favoráveis da instituição e de seus profissionais, principalmente, dos médicos.

Com a presente discussão, este paper buscou compreender como a relação entre a instituição médica e a televisão se estruturou nos Estados Unidos de forma, majoritariamente, positiva e quais benefícios ela pode proporcionar para o espectador e para a sociedade, uma vez que essas produções possuem um elevado potencial informativo. Estudos futuros podem ser de caráter comparativo, analisando a forma como a indústria audiovisual americana e brasileira representam profissionais de saúde e a instituição médica na ficção seriada televisiva. Similarmente, trabalhos sobre as produções nacionais fundamentados 
na perspectiva do Entertainment-Education e na potencialidade educativa dessas produções, como o de Almeida ${ }^{35}$, seriam bem-vindos de modo não só a estimular as discussões no campo dos estudos de saúde e comunicação no Brasil, como também a incentivar um relacionamento mutualístico entre as instituições médicas nacionais e a indústria televisiva.

\section{Referências}

1. Kuipers G. Cultural Globalization as the Emergence of a Transnational Cultural Field: Transnational Television and National Media Landscapes in Four European Countries. Am Beha Sci [Internet]. 2011 Mar [citado em 2017 jun. 13];55(5):541-57. www.dx.doi.org/10.1177/0002764211398078

2. Jost F. Do que as séries americanas são sintoma? Porto Alegre: Sulina; 2012.

3. Buonanno M. The transatlantic romance of television studies and the 'tradition of quality' in Italian TV drama. The Jour of Pop Tel [Internet]. 2013 Set [citado em 2017 jun. 13];1(2):175-89. www.dx.doi. org/10.1386/jptv.1.2.175 1

4. Lotz AD. The television will be revolutionized. New York: NYU Press; 2007.

5. Tryon C. On-Demand Culture: Digital Delivery and the Future of Movies. Camden: Rutgers University Press; 2013.

6. Tryon C. TV Got Better: Netflix's Original Programming Strategies and the On-Demand Television Transition. Me Ind Jour [Internet]. 2015 [citado em 2017 jun. 13];2(2):104-16. http://dx.doi.org/10.3998/ mij.15031809.0002.206

7. Turow J. Playing Doctor. 2nd ed. New York: Oxford University Press; 2010.

8. Reagan L, Tomes N, Treichler P, editors. Medicine's Moving Pictures: medicine, health, and bodies in American film and television. Rochester, NY: University Rochester Press; 2007.

9. Tapper EB. Doctors on Display: the evolution of television's doctors. Proc (Bayl Univ Med Cent) [Internet]. 2010 Out [citado em 2017 Jun 13];23(4):393-9. Disponível em: https://goo.gl/aFuCXT

10. Quick BL. The Effects of Viewing Grey's Anatomy on Perceptions of Doctors and Patient Satisfaction. Jour of Broad \& Elect Med [Internet]. 2009 Mar [citado em 2017 jun. 13];53(1):38-55. https://doi. org/10.1080/08838150802643563

11. Movius L, Cody M, Huang G, Berkowitz M, Morgan S. Motivating Television Viewers to Become Organ Donors. Pub Hea Com \& Mark [Internet]. 2007 Jun [citado em 2017 jun. 13];1-21. Disponível em: https://goo.gl/JMknJM

12. Chory-Assad RM, Tamborini R. Television Doctors: an Analysis of Physicians in Fictional and NonFictional Television Programs. Jour of Broad \& Elect Med [Internet]. 2001 Jun [citado em 2017 jun. 13]; 45(3):499-521. Disponível em: https://goo.gl/CxR5q7

13. Hether HJ, Murphy ST. Sex Roles in Health Storylines on Prime Time Television: A Content Analysis. Sex Rol [Internet]. 2009 Set [citado em 2017 jun. 13];62(11-12):810-21. https://doi.org/10.1007/s11199$\underline{009-9654-0}$

14. Phillips Z, Huang GC, Beck V, Pollard WE. TV Drama/Comedy Viewers and Health Information: 2005 Porter Novelli HealthStyles Survey. A CDC Report. [Internet]. 2005 Nov [citado em 2017 jun. 13]:1-10. Disponível em: https://goo.gl/iWTQXS

15. Holoweiko M. Here's looking at: doctor-patient relations. Good news - the pedestal is gone. Med eco [Internet]. 1998 Out [citado em 2017 jun. 13];75(20):54-67. Disponível em: https://goo.gl/vuRcse

16. Malmsheimer R. Doctors Only: the Evolving Image of the American Physician. New York: Greenwood Press; 1988.

17. Foss KA. "When We Make Mistakes, People Die!": Constructions of Responsibility for Medical Errors in Televised Medical Dramas, 1994-2007. Com Quart [Internet]. 2011 Ago [citado em 2017 jun. 13];59(4): 484-506. https://doi.org/10.1080/01463373.2011.597350

18. Hollywood Health and Society: overview [Internet]. Beverly Hills, CA: Norman Lear Center; 2014 [citado em 2017 jun. 13]. Disponível em: https://goo.gl/DoSGw] 
19. Hospital Sírio-Libanês. Unidade básica: apoio à produção de conteúdos audiovisuais, no formato de série para TV, para fortalecimento da atenção básica [Internet]. São Paulo; 2017 [citado em 2017 jun. 13]. Disponível em: https://goo.gl/KgCz3r

20. Jacobs J. Body Trauma TV. London: British Film Institute; 2003.

21. Feasey R. Masculinity and popular television. Edinburgh: Edinburgh University Press; 2008.

22. Meimaridis M. Dissecando a estrutura narrativa dos seriados médicos americanos [dissertação]. Niterói: Universidade Federal Fluminense; 2017.

23. Jacobs J. 'Hospital Drama'. In: Creeber G, editor. The Television Genre Book. London: British Film Institute; 2002. p.23-6.

24. Philips D. Medicated Soap: the Woman Doctor in Television Medical Drama. In: Carson B, LlewellynJones M, editors. Frames and Fictions on Television: The Politics of Identity within Drama. Portland: Intellect books; 2000. p.50-61.

25. Sepinwall A. The Revolution Was Televised: The Cops, Crooks, Slingers and Slayers Who Changed TV Drama Forever. Austin, TX: Touchstone; 2011.

26. Alexander JC. Culture and Political Crisis: Watergate and Durkheimian Sociology. In Alexander JC, editors. Durkheimian Sociology: Cultural studies. Cambridge: Cambridge University Press; 1988. p.187-224.

27. Karpf A. Doctoring the media: The reporting of health and medicine. London: Routledge; 1988.

28. Spike J. Television Viewing and Ethical Reasoning: Why Watching Scrubs Does a Better Job Than Most Bioethics Classes. The Ame Jour of Bio [Internet]. 2008 Dez [citado em 2017 jun. 13];8(12):11-3. https:// doi.org/10.1080/15265160802495630

29. Singhal A, Rogers EM. Entertainment-education: A communic ation strategy for social change. Mahwah, NJ: Lawrence Erlbaum Associates; 1999.

30. Brodie M, Foehr U, Rideout V, Baer N, Miller C, Flournoy R, et al. Communicating health information through the entertainment media: a study of the television drama ER lends support to the notion that Americans pick up information while being entertained. He Affa [Internet]. 2001 Jan [citado em 2017 jun. 13];20(2):192-9. https://doi.org/10.1377/h/thaff.20.1.192

31. Bouman M. Turtles and Peacocks: Collaboration in Entertainment-Education Television. Com Theo [Internet]. 2002 Jan [citado em 2017 jun. 13];12(2):225-44. Disponível em: https://goo.gl/3PQmAh

32. Valente TW, Murphy S, Huang G, Gusek J, Greene J, Beck V. Evaluating a Minor Storyline on ER About Teen Obesity, Hypertension, and 5 A Day. J Health Commun [Internet]. 2007 Sept [citado em 2017 jun. 13];12(6):551-66. Disponível em: https://goo.gl/uMrP24

33. Hether HJ, Huang GC, Beck V, Murphy ST, Valente TW. Entertainment-Education in a Media-Saturated Environment: Examining the Impact of Single and Multiple Exposures to Breast Cancer Storylines on Two Popular Medical Dramas. Jour of Hea Com [Internet]. 2008 Dez [citado em 2017 jun. 13];13(8): 808-23. https://doi.org/10.1080/10810730701508385

34. Furquim F. Canal Universal estreia a série brasileira 'Unidade Básica'. Veja [Internet]. 2016 Set 8 [citado em 2017 jun. 13]. Disponível em: https://goo.gl/XEEJaA

35. Almeida HB. Educação do corpo: o seriado Mulher e a promoção de mensagens médico-educativas. Est Fem [Internet]. 2017 Jan [citado em 2017 jun. 13];25(1):315-35. http://dx.doi.org/10.1590/1806$\underline{9584.2017 v 25 n 1 p 315}$ 